\title{
Addressing children's health amid the coronavirus disease 2019 pandemic
}

\author{
Young June Choe, MD, PhD ${ }^{1,2}$, Bilal Aurang Zeb Durrani, MBA ${ }^{1}$, Stefan Swartling Peterson, MD, $\mathrm{PhD}^{3,4}$ \\ ${ }^{1}$ United Nations Children's Fund (UNICEF) Seoul Office, Seoul, Korea; ${ }^{2}$ Hallym University College of Medicine, Chuncheon, Korea; ${ }^{3}$ United Nations Children's Fund \\ (UNICEF) Headquarters, New York, NY, USA; ${ }^{2}$ Department of Women's and Children's Health (IMCH), Uppsala University, Uppsala, Sweden
}

\begin{abstract}
Key message
In the coronavirus disease 2019 (COVID-19) pandemic, children experience heightened barriers to health and protective services. Children may also be disproportionately affected due to their reliance on the education system for daily tasks and lack of access to remote learning options. Republic of Korea findings on how vaccination coverage could be sustained in children and schools could be reopened without aggravating COVID-19 underlie the need for coordinated efforts across sectors.
\end{abstract}

The global coronavirus disease 2019 (COVID-19) crisis has brought unprecedented changes in children's routines due to social distancing and confinement. Current data indicate that children are less vulnerable to COVID-19. ${ }^{1)}$ However, the indirect impacts of constrained health systems, limited access to preventative services like vaccinations, childcare disruptions, school closures, and household loss of income, are considerable. Thus, it is critically important to address collateral impacts on children when discussing strategies for mitigating COVID-19.

In many places, COVID-19 has forced the discontinuation of regular health services by overwhelming health system capacities. ${ }^{2)}$ Furthermore, infection control procedures designed to reduce severe acute respiratory syndrome coronavirus 2 (SARS-CoV-2) virus transmission have decreased access to other health services and halted the delivery of some essential childcare services. Specifically, the interruption of immunization services may increase child morbidity and mortality rates in the medium to long term. To date, routine childhood immunization services have been disrupted globally, with more than half of the 129 countries reporting disruptions to vaccination services during March and April 2020. ${ }^{3)}$ These disruptions occurred not only in low- and middle-income countries; rather, even highincome countries like the United States experienced a decline in vaccination coverage following the declaration of national emergency in March 2020.4) In contrast, the vaccination coverage was relatively sustained in the Republic of Korea. Compared to corresponding months in 2019, minimal decreases in vaccination coverage rates were noted in January to March
2020: vaccines for infants aged $<12$ months (Bacille CalmetteGuérin, hepatitis B, diphtheria-tetanus-acellular pertussis [DTaP], inactivated polio vaccines) sustained coverages at 97\%$98 \%$ in 2020; the first measles-mumps-rubella vaccine dose from $95.9 \%$ (2019) to $95.0 \%$ (2020), the fourth DTaP vaccine dose from $90 \%$ (2019) to 87\% (2020), and the fourth Japanese encephalitis vaccine dose from $88 \%$ (2019) to $86 \%(2020)$. $^{5}$ The smaller decline in vaccination coverage in Korean children suggests that system-level strategies to maintain well childcare and immunization are in place (Table 1). Sustained vaccination coverage in children reflects the success of previous strategies to promote the expansion of childhood vaccinations including outreach to private clinics and a school-based certificate system. With the long-standing history of the universal vaccination program supported by public funding in Korea, the system has evolved to incorporate evidence-based policy making through a national immunization technical advisory group. Vaccination registrations are mandated for reimbursement to the private sector; for the next vaccination schedule, a text message is routinely sent for reminder-recall purposes. $\left.{ }^{6}\right)$ This communitybased partnership between the public and privatized system has enabled this sustained level of vaccination coverage during the COVID-19 pandemic.

As of July 13, 2020, 109 countries had implemented countrywide school closures to mitigate the COVID-19 pandemic, affecting an estimated $60.5 \%$ of students globally. ${ }^{7}$ School closures worsen the learning gap since children from poorer

Table 1. Key components of national immunization program of Republic of Korea

Key components of national immunization program

Support the vaccine \& vaccination expenses

Expansion of vaccine accessibility

School entry requirement of certification

Measles Elimination Program

Hepatitis B Perinatal Transmission Prevention Program

Adverse Event Following Immunization Management System

Electronic Immunization Registry

Corresponding author: Young June Choe, MD, PhD. Department of Social and Preventive Medicine, Hallym University College of Medicine, 1, Hallymdaehak-gil, Chuncheon 24252, Korea 
families fall further behind, while wealthier children may continue schooling using digital tools. Moreover, many children who rely on school meals are deprived. As one of the earliest hit countries with COVID-19, the Republic of Korea closed most schools until May 2020 and began the first stepwise reopening. The plan included precautionary measures of infection control and a preparedness plan (Table 2). Local class or school closures were allowed based on local infection rates in conjunction with in-school health and safety measures, while students continued distance learning at home. Between May 1 and July 12, 2020, a total of 127 school-aged pediatric COVID-19 cases were confirmed in Korea when schools opened for in-person (faceto-face) classes on May 20. Among them, only 2\% $(\mathrm{n}=3)$ were exposed to SARS-CoV-2 in the public education system.8) This finding is in line with reports from Norway and Ireland that, in the setting of vigilant infection control and prevention planned in schools, COVID-19 transmission in schools can be limited. ${ }^{9,10)}$ These findings from Korea suggest that the reopening of schools following standardized measures applied to schools such as detailed guidance for school closure, disinfection, and contact management did not aggravate the course of COVID-19 resurgence in children.

Mobilizing sufficient financing remains a major challenge in implementing the 2030 Agenda for Sustainable Development

Table 2. COVID-19 prevention guidelines for kindergartens, elementary, middle, and high schools, Republic of Korea

\begin{tabular}{l} 
General guideline \\
Manection for COVID-19 response measures \\
Measures to infection control within schools \\
General response measures: before school hours, going to school, \\
during school hours, during lunch break \\
Response measures in case of suspected cases \\
Response measures in case of confirmed cases \\
Management of dormitories and other facilities \\
Specific workflow \\
Check list for prevention and management of CoVID-19 \\
Guidelines for monitoring fever at school \\
Correct methods for temperature checks \\
Guidelines for disinfection at school \\
Guidelines for using masks \\
Guidelines for the use of air conditioners \\
Restriction of school facilities in case of confirmed cases at school \\
Guidelines for students and parents \\
Psychological support for students after school \\
Mental health support for students in self-isolation \\
Guidelines for prevention of infectious diseases \\
Code of conduct \\
School rules \\
Quarantine measures at kindergartens \\
Code of conduct for people in self-isolation \\
\hline OVID-19, coronavirus disease 2019. \\
of conduct for people subject to self-isolation \\
\hline
\end{tabular}

OVID-19, coronavirus disease 2019. and achieving the Sustainable Development Goals. Horizontal cooperation - the exchange of knowledge, expertise, and technology—remodels the development finance landscape. As a signatory to the UN General Assembly Resolution on Buenos Aires outcome document of the second High-level United Nations Conference on South-South Cooperation, the Korean government is keen to champion international development cooperation by sharing its experience, lessons learned, good practices, knowledge, and expertise with other countries through horizontal cooperation. While Korea's traditional forms of international development cooperation (grants, loans, and trade) remain relevant and growing, new complementary approaches such as horizontal cooperation through United Nations Children's Fund (UNICEF)'s offices in over 190 countries and territories will help end its dependence on long-established financial mechanisms. We are now happy to include specific Korean examples and lessons learned in mitigating COVID-19 in Korea's contributions.

\section{Conflicts of interest}

No potential conflict of interest relevant to this article was reported.

\section{Acknowledgments}

We thank staff members of UNICEF Seoul Office for their support and contribution in preparation of this manuscript.

\section{References}

1. Green P. Risks to children and young people during covid-19 pandemic. BMJ 2020;369:m1669.

2. Kinross P, Suetens C, Gomes Dias J, Alexakis L, Wijermans A, Colzani E, et al. Rapidly increasing cumulative incidence of coronavirus disease (COVID-19) in the European Union/European Economic Area and the United Kingdom, 1 January to 15 March 2020. Euro Surveill 2020;25: 2000285.

3. Ministry of Education, Ministry of Health and Welfare, Ministry of Food and Drug Safety. Coronavirus disease 2019 infection prevention management guideline in schools, version 2-2 [nternet]. Sejong (Korea): Ministry of Education; 2020 [2020 Jul 15]. Available from: https://www. moe.go.kr/.

4. Santoli JM, Lindley MC, DeSilva MB, Kharbanda EO, Daley MF, Galloway L, et al. Effects of the COVID-19 pandemic on routine pediatric vaccine ordering and administration - United States, 2020. MMWR Morb Mortal Wkly Rep 2020;69:591-3.

5. Van Lancker W, Parolin Z. COVID-19, school closures, and child poverty: a social crisis in the making. Lancet Public Health 2020;5:e243-4.

6. Choe YJ, Yang JJ, Park SK, Choi EH, Lee HJ. Comparative estimation of coverage between national immunization program vaccines and non-NIP vaccines in Korea. J Korean Med Sci 2013;28:1283-8.

7. United Nations Educational, Scientific and Cultural Organization (UNESCO). COVID-19 impact on education [Internet]. Paris: UNESCO; 2020 [2020 Aug 30]. Available from: https://en.unesco.org/covid19/ educationresponse.

8. Kim EY, Ryu BY, Kim E, Park YJ, Choe YJ, Park HK, et al. Children with COVID-19 after reopening of schools, South Korea. Pediatr Infect Vaccin 2020, In Press.

9. Heavey L, Casey G, Kelly C, Kelly D, McDarby G. No evidence of secondary transmission of COVID-19 from children attending school in 
Ireland, 2020. Euro Surveill 2020;25:2000903.

10. Johansen TB, Astrup E, Jore S, Nilssen H, Dahlberg BB, Klingenberg C, et al. Infection prevention guidelines and considerations for paediatric risk groups when reopening primary schools during COVID-19 pandemic, Norway, April 2020. Euro Surveill 2020;25:2000921.
How to cite this article: Choe YJ, Aurang Zeb Durrani B, Peterson SS. Addressing children's health amid the coronavirus disease 2019 pandemic. Clin Exp Pediatr 2021;64:46-48. https://doi.org/10.3345/cep.2020.01473 